\title{
LA REFORMA AL DERECHO DE OBLIGACIONES Y CONTRATOS EN FRANCIA. UN ANÁLISIS PRELIMINAR
}

\author{
Rodrigo Momberg Uribe \\ Universidad de Oxford \\ y Universidad Católica del Norte
}

\section{INTRODUCCIÓN}

Cuando el año 2004 el Code civilfrancés conmemoró su segundo centenario, uno de los temas principales fue la discusión sobre la necesidad, pertinencia y contenido de una reforma al Derecho de Obligaciones y Contratos. Lo mismo que en Chile, la regulación de dicha materia ha permanecido casi sin modificaciones desde la entrada en vigencia del Code. El desarrollo del Derecho francés de obligaciones y contratos se ha producido fuera del Code, a través de legislación especial o por medio de la jurisprudencia de la Cour de Cassation 1 .

La presentación por parte del Ministerio de Justicia francés de el Proyecto ${ }^{2}$ representa el episodio final de dicho debate. Después de una tramitación no exenta de polémica, que finalizó con una decisión del consejo constitucional declarando la consti-

${ }^{1}$ Vogenauer (2009), pp. 4-7.

${ }^{2} \mathrm{El}$ proyecto se encuentra disponible en www.justice.gouv.fr/publication/j21_projet_ord_reforme_contrats_2015.pdf. La Fondation pour le droit continental ha traducido el Proyecto al español, disponible en www. justice.gouv.fr/art_pix/projet_reforme_contrats_2015_espagnol.pdf. [Fecha de consulta: 30 de abril de 2015]. tucionalidad de la ley delegatoria ${ }^{3}$, el Ejecutivo francés ha obtenido la autorización del Parlamento para efectuar la reforma del Code Civil por medio de una ordenanza, lo que implica que el contenido proyecto no será discutido en el Parlamento, el cual se limitará a ratificar o rechazar el texto que, en definitiva, se le presente por el Ejecutivo ${ }^{4}$. Según el cronograma presentado por el Ministerio de Justicia, ello debería suceder a más tardar durante el primer semestre de 2016.

Como se explicará a continuación, la presentación de el Proyecto tiene relación con el objetivo general de volver a situar al Derecho Privado francés como un derecho atractivo en el ámbito internacional, de modo que recupere la influencia que gradualmente ha perdido frente a las partes, tribunales y legisladores. Asimismo, se busca aumentar la inteligibilidad y accesibilidad del Derecho de Contratos y Obligaciones del Code

${ }^{3}$ Decisión No $2015-710$ de 12 de febrero de 2015.

${ }^{4}$ Ley No $2015-177$ de 16 de febrero de 2015, sobre modernización y simplificación de derecho y los procedimientos en el ámbito de la justicia y los asuntos internos. 
civil, mediante su actualización a los desarrollos que la doctrina, la jurisprudencia y la sociedad en general, han experimentado en los últimos doscientos años ${ }^{5}$.

El propósito de este artículo es proveer una visión general de dicho proyecto, sus antecedentes, estructura y contenido, en particular a lo que se refiere a la regulación que propone de la parte general del Derecho de Contratos $^{6}$. El análisis se efectuará incorporando referencias al Derecho Uniforme de Contratos cuando sea pertinente.

\section{II.- LOS PROYECTOS DE REFORMA DESPUÉS DEL BICENTENARIO}

\section{a) Antecedentes}

122 delo francés, la cual se extiende por Europa, Asia, África, Latinoamérica e, incluso, jurisdicciones de Norteamérica, como Luisiana y Quebec.

Sin embargo, al mismo tiempo, existía un sentimiento de frustración y desencanto: sin perjuicio de sus méritos, el siglo XXI encontraba al Code como un texto desactualizado, de manera que según algunos autores, la lectura de los titulos III y IV del libro III del Code Civil no permite siquiera obtener un conocimiento remoto del Derecho de Contratos y de Responsabilidad Extracontracual vigente hoy en Francia ${ }^{7}$. Como se dijo, el desarrollo del Derecho de Obligaciones y Contratos se ha producido fuera del Code, a través de legislación especial o por medio de la jurisprudencia de la Cour de Cassation, haciendo difícil para el ciudadano común aun para la comunidad jurídica, la comprensión y el acceso a la ley ${ }^{8}$.

También, y quizá como consecuencia de lo anterior, la enorme influencia que el Code ejerció durante el siglo XIX y la primera parte del xx ha disminuido considerablemente. Las reformas y nuevas codificaciones que han tenido lugar en jurisdicciones pertenecientes (o que pertenecieron) a la denominada familia francesa, paradójicamente han abandonado en gran medida el modelo francés, prefiriendo otras fuentes de inspiración. Así, por ejemplo, en Latinoamérica han sido el Codice Civile italiano y el alemán los que más han influido en las reformas o nuevas codificaciones que se han efectuado durante los siglos XX

\footnotetext{
${ }^{7}$ Catala (2007), p. 182.

${ }^{8}$ Véase SARGos (2009). p. 383.
} 
y XXI. Lo mismo ha sucedido con los países pertenecientes a la OHADA, muchos de ellos ex colonias francesas, los cuales en vez de recurrir al derecho francés, decidieron buscar la asesoría de UNIDROIT (y, por tanto, la inspiración en los Principios UNIDROIT sobre Contratos Comerciales Internacionales) para la redacción de su Ley Uniforme sobre Derecho de Contratos (Acte uniforme OHADA sur le droit des contrats) $)^{9}$.

Otro golpe importante al Derecho Privado francés lo constituyó el Informe del Banco Mundial Doing Bussiness in 2004: Understandig Regulation, en el cual el deficiente desempeño de ciertos índices económicos se vinculaba a la pertenencia del sistema jurídico del país en cuestión a la tradición francesa ${ }^{10}$. Si bien la respuesta de la comunidad jurídica francesa fue vigorosa, criticando no solo (de manera justificada) la metodología utilizada en el informe sino, también, proveyendo argumentos plausibles en defensa del Derecho sustantivo francés ${ }^{11}$, hubo

${ }^{9}$ Fontaine (2004).

${ }^{10} \mathrm{El}$ informe se encuentra disponible en www.doingbusiness.org/ /media/GIAWB/ Doing\%20Business/Documents/AnnualReports/English/DB04-FullReport.pdf. [Fecha de consulta: 11 de abril de 2015].

${ }^{11} \mathrm{Al}$ respecto, véase, por ejemplo, Association Henri Capitant (2006). También, con el objetivo de promover el atractivo económico del Derecho francés, el Programme international de recherche "Attractivite Economique du Droit", https://ufr-dsp.u-paris10.fr/ufr-dspdroit-et-science-politique-/les-enseignants/ pages-des-enseignants-chercheurs/du-marais/ programme-attractivite-economique-dudroit-a-l-universite-paris-ouest-nanterrela-defense-227248.kjsp?RH=Pgrm+AED. La creación de la Fondation pour le droit continental también puede considerarse una también cierto consenso en que la falta de actualización del Derecho Privado y, en particular, del Derecho de Obligaciones y Contratos contenido en el Code, era un factor contrario a la "exportabilidad" del Derecho francés.

Por último, el Derecho francés de Obligaciones se vio, al menos de manera inicial, sustancialmente marginado del proceso de armonización y unificación del Derecho de Contratos europeo. En un principio, ello se debió al escepticismo e, incluso, resistencia de los juristas franceses al proceso, el cual fue asumido, entre otras cosas, como una amenaza a la idea de codificación como reflejo de identidad nacional. No obstante, esta hostilidad llevó a que los instrumentos producto de dicho proceso recibieran escasa influencia del Derecho francés. Pese a que ante la inexorabilidad del proceso, una parte de la doctrina francesa terminase incorporándose al mismo ${ }^{12}$, de nuevo, la falta de actualización del Derecho de Obligaciones y Contratos contenido en el Code hizo difícil que este pudiese ejercer una influencia significativa.

\section{b) El Avant-projet Catala}

Los antecedentes mencionados en el apartado precedente fueron los

respuesta al informe, www.fondation-droitcontinental.org/fr/. [Fecha de consulta: $11 \mathrm{de}$ abril de 2015].

${ }^{12}$ Así sucedió con el grupo de trabajo conformado por la AHC-SLC Group que se incorporó al proyecto de elaboración del Marco Común de Referencia. Como producto del trabajo del grupo se publicaron los volúmenes Principes contractuels... (2008) y Terminologie contractuelle... (2008), y FAuvarque-Cosson, Mazeaud (eds.) (2008). 
detonantes para la elaboración del primer proyecto posterior al bicentenario, el Avant-projet de réforme du droit des obligations et de la prescription, más conocido como el Avant-projet Catala, en honor a su principal artífice, el profesor Pierre Catala ${ }^{13}$. Si bien la elaboración del proyecto, en un principio, recibió apoyo político por parte de las autoridades francesas y su texto fue sometido a consulta pública por parte del Ministerio de Justicia, finalmente no fue presentado para su discusión legislativa. Sin perjuicio de lo anterior, el Avant-projet fue objeto de una amplia difusión y discusión académica no solo en Francia sino, también, en el ámbito internacional ${ }^{14}$. Asimismo, fue traducido al alemán, español, inglés e italiano ${ }^{15}$.

En cuanto al fondo, el Avant-projet 124 Catala puede ser considerado conservador, o como lo señaló expresamente su gestor,

"el Anteproyecto no propone un Código de ruptura, sino de adecuación" ${ }^{16}$.

Dicho carácter fue justamente el objeto principal de las críticas al proyecto, sobre todo tomando en cuenta que

${ }^{13}$ Como su nombre lo manifiesta, el proyecto comprende no solo el Derecho de Obligaciones sino, también, de la responsabilidad extracontractual y de la prescripción.

${ }^{14}$ A modo de ejemplo, los coloquios organizados por la Revue des contrats, disponibles en Revue des contrats, $\mathrm{N}^{\mathrm{O}} 1$, Paris, 2006 y $\mathrm{N}^{\mathrm{O}} 1$. Paris, 2007 y CARTwright, VogeNAUER \& WhitTAKER (2009).

${ }^{15}$ Disponibles en www.henricapitant.org/ node/73. [Fecha de consulta: 11 de abril de 2015].

${ }^{16}$ Catala (2006). uno de sus propósitos principales era reposicionar al Derecho francés en el ámbito internacional ${ }^{17}$. Sin embargo, el Avant-projet carece casi por completo de un análisis de Derecho Comparado, ignorando instituciones reconocidas con amplitud en otras jurisdicciones

"perseverando en reglas que son fuertemente criticadas internamente y mayoritariamente abandonadas en legislaciones modernas" $"$.

El paradigma en este sentido es la decisión del proyecto de conservar la causa como requisito de existencia del contrato (arts. 1124-1126-1). No hay, tampoco, un reconocimiento explícito a la buena fe como principio general y las facultades del juez en casos de imprevisión son limitadas. De igual forma, instituciones aceptadas en el ámbito internacional como el anticipatory breach no fueron recogidas por el proyecto ${ }^{19}$.

Sin perjuicio de las criticas mencionadas, debe reconocerse que el Avant-projet concedió mayor relevancia que el Code al papel de la justicia sustantiva en materia contractual, estableciendo deberes de información y lealtad (v.gr., arts. 1104, 1110, 1120) y velando por el equilibrio contractual (v.gr., arts. 1114-3, 1122-2 y 1135-1). También, en general, el papel de la buena fe y del juez frente a los con-

${ }^{17}$ Vogenauer (2009), pp. 20-21.

${ }_{18}^{18}$ Tallon (2006), p. 131.

${ }^{19} \mathrm{Al}$ efecto, véase Hondius (2007), pp. 835839. 
tratantes es fortalecido, por ejemplo, concediendo al juez la facultad de revisar o suprimir una cláusula que causa un detrimento considerable a unos de los contratantes (art. 1122-2), de ordenar la renegociación del contrato en caso de excesiva onerosidad sobrevenida (art. 1135-2) o conceder un plazo al deudor para que cumpla su obligación (art. 1158-1).

\section{c) El proyecto de la Chancellerie}

En julio de 2008 el Ministerio francés de Justicia presentó un nuevo proyecto de reforma, esta vez limitado al Derecho de Obligaciones y Contratos, sin incluir la responsabilidad extracontractual ${ }^{20}$. El proyecto fue elaborado por un grupo de trabajo que incluyó jueces y a la profesora Benedicte Fauvarque-Cosson.

El proyecto, si bien sigue al Avantprojet Catala en una serie de aspectos, es un instrumento más europeo y menos localista, que reconoce la influencia de los PECL y los PICC ${ }^{21}$. Así, en materia de imprevisión, el art. 136 permite la adaptación judicial del contrato en el caso que la renegociación del mismo haya fracasado, sujeto a que las partes le hayan conferido dicha facultad. Más importante, suprime el requisito de la causa y lo reemplaza por el de interés, tal como se detallará más adelante (arts. 49, 85 a 87). Asimismo, establece expresamente tres principios generales (principes directeurs): la libertad de contratación,

${ }^{20}$ Las normas sobre prescripción fueron reformadas en junio de 2008 (Ley N ${ }^{\circ}$ 2008-561 de 17 de junio de 2008).

${ }^{21}$ Castets Renard (2010), pp. 65-86. la fuerza obligatoria del contrato y la buena fe (arts. 15 a 18) ${ }^{22}$.

La recepción de la doctrina al proyecto de la Chancelleriefue mixta, siendo la supresión de la causa la mayor fuente de disputas ${ }^{23}$. En cambio, el Colegio de Abogados (Conseil National des Barreaux) y la Cámara de Comercio de París, se mostraron favorables a las reformas propuestas ${ }^{24}$.

\section{d) El proyecto Terré}

Finalmente, un tercer proyecto fue presentado en diciembre de 2008. El proyecto fue elaborado por un grupo de académicos y abogados destacados, al cual se sumó un representante de la Cámara de Comercio de París, todos liderados por el profesor François Terré, presidente de la Academia de Ciencias Morales y Políticas $^{25}$. El denominado Proyecto Terré es el más rupturista de los proyectos previos al que se comenta ${ }^{26}$.

${ }^{22}$ Una presentación general del proyecto en Revue des contrats. $\mathrm{N}^{\circ} 1$, Paris. 2009.

${ }^{23}$ Una visión crítica en CABRILLAC (2008), p. 190 y una positiva en FABre-Magnan (2008), p. 199.

${ }^{24} \mathrm{Al}$ efecto, véase http://cnb.avocat.fr/ Projet-de-reforme-du-droit-des-contrats-untexte-equilibre-elabore-en-concertation-conforme-a-la-pratique_a525.html [Fecha de consulta: 09 de abril de 2015]; y Chambre de commerce et d'industrie de Paris, Vers un droit des contrats modernisé et mieux adapté à la vie des affaires: Réaction de la CCIP à la consultation de la Chancellerie de juillet 2008 (2008), www. etudes.ccip.fr/archrap/pdf08/reforme-droitdescontrats-kli0810.pdf. [Fecha de consulta: 9 de abril de 2015]

${ }^{25} \mathrm{El}$ texto del proyecto, junto con una serie de artículos relativos a las reformas propuestas, fueron publicados en TERRÉ (2009).

${ }^{26}$ En este sentido, Denis Mazeaud califica al proyecto como un texto de ruptura que im- 
Así, la causa es completamente suprimida como requisito de existencia del contrato, sin ser reemplazada por un concepto equivalente, como el de interés (art. 13); se sancionan de forma en virtud del estado de necesidad o vulnerabilidad de la contraparte, otorgando al juez la facultad de modificar el contrato (art. 66); y para el caso de imprevisión, se concede derechamente al juez la facultad de adaptar el contrato o de ponerle término en las condiciones que estime convenientes (art. 92).

III. DESCRIPCIÓN GENERAL del Proyecto de Ordenanza. ESTRUCTURA Y CONTENIDO

126 clara los contratos lesionarios en que se ha obtenido una ventaja excesiva

III del título III), que comprende a los cuasicontratos y, en particular, a la gestión de negocios, el pago de lo no debido y el enriquecimiento injustificado.

Adicionalmente, el actual título IV del Code es reemplazado por uno nuevo denominado "Del régimen general de las obligaciones" y sucede lo mismo con el título IV bis que regula "De la responsabilidad por productos defectuosos", modificado por el intitulado "De la prueba de las obligaciones".

\section{b) El contenido}

El objetivo de este trabajo es presentar esencialmente el nuevo régimen que para la parte general del Derecho de Contratos se propone, por lo que a continuación se efectuará un análisis general del contenido del subtítulo I del título III, relativo al contrato. Dicho subtítulo se divide a su vez en cuatro capítulos: Disposiciones preliminares, Formación del contrato, Interpretación del contrato y Efectos del contrato.

en general" y "De las obligaciones que se contraen sin convención" respectivamente, son reemplazados por un nuevo título III denominado "De las fuentes de las obligaciones". Así, sin enumerarlas en una disposición particular, el Proyecto establece como fuentes de las obligaciones al contrato (subtítulo I del título III), la responsabilidad extracontractual (subtítulo II del título III, al cual se trasladan los actuales arts. 1382 a 1386-18) y "Otras fuentes de obligaciones" (subtítulo

plica "una pequeña revolución contractual". Mazeaud (2010). b. 1) Principios generales.

Concepto y clasificación de los contratos

El capítulo I comienza, al igual que lo hace el texto vigente del Code, con una definición de contrato, pero que se aleja de la conceptualización clásica al señalar:

"Un contrato es un acuerdo de voluntades entre dos o más personas destinado a crear efectos de derecho" (art. 1101 del proyecto). 
Las diferencias con la definición vigente son evidentes. El actual art. $1101 \mathrm{del}$ Code Civil dispone:

"El contrato es una convención por la cual una o varias personas se obligan, respecto de una o varias más, a dar, hacer o no hacer algo".

No hay, entonces, mención a la convención, a la obligación ni a las prestaciones objeto de la misma. Se ha optado por abandonar, al menos de la terminología de la reforma, a la convención y al acto jurídico, centrándose la regulación en la figura del contrato como un acuerdo, tal como sucede en las codificaciones modernas y en los instrumentos de derecho uniforme ${ }^{27}$.

A continuación de la definición de contrato, se establecen (aunque sin denominarlos como tales) dos principios generales, ausentes de formulación explícita en el texto actual: la libertad de contratación (art. 1102) y la buena fe (art. 1103). La consagración expresa de este último principio, presente en el texto vigente del Code, a propósito de la ejecución del contrato (inc. 3 del actual art. 1134), es reflejo de la tendencia general al otorgar un papel relevante a la buena fe en todo el iter contractual $^{28}$. Así, solo a modo de ejemplo, el deber de actuar de buena fe es establecido como principio general en los arts. 1.7. de los PICC, 1:201 de los PECL, 6:2 del Código Civil holan-

${ }^{27}$ Al efecto, véase Witz (2009), pp. 51-65, quien destaca la confusión y dificultades sistemáticas y de interpretación que conlleva la consagración legal de los conceptos de contrato y convención.

${ }^{28}$ Vogenauer (2015), p. 205. dés, 7 del Código Civil español, 422 del Código Civil brasilero y 9, 729 y 961 del reciente Código Civil argentino. Asimismo, aunque el Common Law inglés se mantiene reticente a utilizar la expresión "buena fe", no sucede lo mismo con otras jurisdicciones del Common Law como Estados Unidos, Australia y Canadá, en las cuales ha ido adquiriendo importancia en las últimas décadas ${ }^{29}$. Sin embargo, el proyecto, a diferencia de otros instrumentos como el DCFR (art. I.- 1:103) no define qué debe entenderse por buena fe, dejando, por tanto, la determinación del concepto a los tribunales para cada caso concreto ${ }^{30}$.

Los artículos siguientes efectúan una clasificación de los contratos, donde destaca la introducción de los contratos negociados de forma libre (literalmente, de común acuerdo, de gré à grè), de adhesión (art. 1108), los contratos marco (art. 1109), los contratos de ejecución instantánea y los de ejecución sucesiva (art. 1110).

\section{b. 2) La formación del contrato}

El capítulo II sobre formación del contrato contiene una sección por completo novedosa para el Code, relativa al proceso de conclusión del contrato, un tema ausente de la mayoría de los códigos decimonónicos ${ }^{31}$, y que

${ }^{29}$ Véase las referencias en Vogenauer (2015).

${ }^{30}$ En este sentido, Aubert de Vincelles (2009), p. 117.

${ }^{31}$ En Francia la ausencia de regulación en la materia es absoluta, a diferencia del caso chileno donde las reglas del título IX del libro II del Código de Comercio, sobre "La constitución, forma y efectos de los contratos y obligaciones" se han entendido de aplicación general. 
incluye, en la regulación propuesta, las negociaciones (subsección 1), la oferta y la aceptación (subsección 2), la promesa unilateral y el pacto de preferencia (subsección 3) y el contrato celebrado por vía electrónica (subsección 4). La necesidad de efectuar una regulación de esta materia, y así evitar la incertidumbre vigente, ha sido destacada por la doctrina y otras partes interesadas ${ }^{32}$.

La mencionada subsección 1 establece el principio de la libertad para entrar, mantenerse y terminar las negociaciones precontractuales, respetando las exigencias de la buena fe. Además, se establece que en el caso de conducta o ruptura culposa no podrán reclamarse los beneficios o ganancias que habría reportado la celebración del contrato, indemnizándose, por 128 tanto, solo el denominado el interés negativo (art. 1111). La normativa propuesta se construye sobre la base de la jurisprudencia de la Cour de cassation, que a partir de las reglas sobre responsabilidad extracontractual ha determinado la existencia y características de la responsabilidad precontractual en el derecho francés ${ }^{33}$. Las normas propuestas son también coherentes con las del Derecho Uniforme, como

\footnotetext{
32 Aubert de Vincelles (2009), citando a la Cámara de Comercio de París.

${ }^{33}$ Com. 11 de junio de 1996, RTD civ. 1997, 120, obs. Jacques Mestre. Sobre la calificación de esta responsabilidad como extracontractual, Com. 12 de febrero de 2002, CCC 2002, 90, obs. Laurent Leveneur y sobre la limitación de la indemnización al interés negativo, Com. 26 de noviembre de 2003, Bull. Civ. IV, N $^{\circ} 186$, D. 2004 , p. 869 , nota Anne-Sophie DupréDallemagne; Civ. $3^{\text {a }}, 28$ de junio de 2006, Bull. civ. III N ${ }^{\circ} 168$, JCP 2006 II, 10130, obs. Olivier Deshayes.
}

los arts. 2.1.5 los PICC, 2:301 de los PECL y II.- 3:301 del DCFR.

La regulación de la oferta y la aceptación presenta también algunos puntos de interés (subsección 2). De acuerdo con el art. 1114, la oferta comprende los elementos esenciales del contrato propuesto y puede ser hecha a persona determinada o indeterminada ${ }^{34}$. Además, el Proyecto distingue entre retractación (art. 1115) y revocación (art. 1116). El oferente puede retractarse hasta antes de que la oferta haya llegado al conocimiento del destinatario, en lo cual el Proyecto sigue a los PICC (art. 2.1.3) que señala que una oferta, aun cuando sea irrevocable, puede ser retirada si el retiro llega al destinatario antes o al mismo tiempo que la oferta.

En cuanto a la revocación, la oferta no puede ser revocada antes del plazo estipulado, o en su defecto, antes de un plazo razonable (art. 1116). Esta regla también ha sido reconocida por la jurisprudencia de la Cour de cassation $^{35}$. La revocación extemporánea

${ }^{34}$ Aceptan la oferta a persona indeterminada los PECL (art. 2:202 (2) y (3)) y el DCFR (art. II.- 4:201). En cambio, se entiende que el art. 2.1.2 de los PICC presume que una propuesta al público o a persona indeterminada es meramente una invitación a formular una oferta, siguiendo la regla del Derecho inglés y alemán en la materia. Véase NotTage (2015), pp. 267-268.

${ }^{35}$ Civ. $3{ }^{\text {a }} 25$ de mayo de 2005, Bull. Civ. III $\mathrm{N}^{\mathrm{O}} 117$, D. 2005, p. 2837, obs. Soraya Amrani Mekki. Los instrumentos de Derecho Uniforme establecen una regla ligeramente diversa, ya que señalan que la oferta no podrá revocarse (además del caso de irrevocabilidad expresa) cuando el destinatario pudo modo razonable considerar que la oferta era irrevocable y haya actuado en consonancia con dicha oferta (art. 2.1.4(2)(b) de los PICC y 2:202(3)(c) de los PECL). 
solo genera responsabilidad extracontractual del oferente, $y$ al igual como sucede con la ruptura culposa de las negociaciones, solo se indemniza el interés negativo (art. 1117). La regla es acorde con la jurisprudencia francesa, descartándose así la alternativa de no otorgar efecto a la revocación y entender que el contrato ha sido perfeccionado, como lo hacían los proyectos de reforma anteriores y una parte de la doctrina ${ }^{36}$.

Respecto al tiempo del perfeccionamiento del contrato, el art. 1122 estipula que este se entiende perfeccionado al momento en que la aceptación llega al oferente. Se acoge, entonces, la denominada "teoría de la recepción". Se decide así una materia sobre la cual no había acuerdo en el Derecho francés, existiendo fallos y doctrina que optaban por la "teoría de la emisión" ${ }^{37}$. El Avant-projet Catala (art. 1107) y el Proyecto Terré (art. 21) optaban también por la teoría de la recepción, lo mismo que los PECL (art. 2:205(1) y (2)) y los PICC (art. 2.1.6(2) $)^{38}$.

${ }^{36}$ Art. 1105-4 Avant-projet Catala y art. 18 inc. 2 Proyecto Terré, esta última norma limitada a las ofertas a persona determinada. Referencias a la doctrina en AUBERT DE VINCELLES (2009), pp. 127-128. Los PECL parecen también adoptar esta solución, al disponer en su art. 2:202(3) que en ciertos casos, la revocación de la oferta "carece de efecto".

${ }^{37}$ Com. 7 de enero de 1981, Bull. Civ. Iv, No 14, RTD civ., 1981, p. 849, obs. François Chabas.

${ }^{38}$ Sin embargo, los PICC y los PECL regulan también la situación en que cuando el destinatario puede indicar su aceptación ejecutando un acto sin notificación al oferente, el contrato se perfecciona al ejecutarse dicho acto (art. 2:205(3) de los PECL y 2.1.6(3) de los PICC). b. 3) La validez del contrato

La sección 2 del capítulo II, sobre la validez del contrato, contiene algunas de las novedades más importantes del proyecto. El art. 1127 señala:

"Son necesarios para la validez del contrato: $1^{\circ} \mathrm{El}$ consentimiento de las partes; $2^{\circ}$ La capacidad de contratar; $3^{\circ}$ Un contenido lícito y cierto".

Se elimina, así, como requisito para la validez del contrato no solo a una de las instituciones insignes del Derecho Privado francés, la causa (la cause), a la que se aludirá más adelante, sino, también, al objeto (l'objet), reemplazando ambos por el ya mencionado "contenido licito y cierto".

La subsección sobre el consentimiento dedica un artículo al "Deber de información", otra novedad del proyecto. En él se establece que aquel contratante que conozca o deba conocer una información cuya importancia es determinante para el consentimiento de la otra, debe informarla si aquella ignora legítimamente la información o actúa confiando en el co-contratante. La infracción al deber de información genera responsabilidad extracontractual, pero si a su vez constituye un vicio del consentimiento (por ejemplo, la omisión conduce a error o constituye dolo), la sanción es la nulidad del contrato (art. 1129). El proyecto opta por establecer un deber de información autónomo, cuya sanción natural es la indemnización de perjuicios y eventualmente la nulidad del contrato si llega a constituir un vicio del consentimiento, alejándose de los 
PICC y los PECL que solo vinculan la omisión de información relevante a casos de error y dolo (arts. 3.2.2 y 3.2.5 de los PICC, y 4:103, 4:107 de los PECL).

El párrafo tercero de la mencionada subsección, se refiere a los vicios del consentimiento: el error, el dolo y la fuerza

"cuando son de tal naturaleza que, sin ellos, una de las partes no hubiese contratado o lo hubiese hecho en condiciones sustancialmente distintas",

debiendo establecerse el carácter determinante del vicio en consideración a las personas y a las circunstancias del caso (art. 1130).

En la regulación de esta materia, 130 destaca la inclusión expresa del error de derecho (art. 1131) y de la omisión dolosa (art. 1136) como eventuales vicios.

La normas sobre error mantienen la tradición subjetiva francesa, admitiendo el error cuando es excusable y recae sobre las cualidades esenciales de la cosa o del otro contratante en los contratos intuito personae (arts. 1131 a 1133), descartando los errores sobre los simples motivos o sobre el valor de la $\cos ^{39}$. No se ha seguido la regla de los PECL (art. 4:103) y los PICC (3.2.2), que establece una causal general de nulidad por error sin distinguir ni hacer mención al objeto sobre el cual recae el mismo, lo cual es reflejo de una concepción que preten-

${ }^{39}$ Sobre las razones para conservar la tradición subjetiva francesa, véase REMY-CORLAY y Fenouillet (2009), pp. 157-161. de dar más relevancia a la seguridad jurídica por sobre la protección de la voluntad individual (subjetiva) de las partes, restringiendo en gran medida la posibilidad de nulidad del contrato por error unilateral ${ }^{40}$.

En relación con el dolo, resalta la incorporación del dolo de un tercero como vicio si el contratante lo conocía y ha obtenido ventaja del mismo (1137). Asimismo, se establece expresamente que el error provocado por el dolo es siempre excusable y vicia el consentimiento aun cuando recaiga sobre el valor de la prestación o un simple motivo (art. 1138), sin perjuicio de que en caso de la reticencia dolosa se requiera una obligación legal de informar (art. 1136), confirmado la jurisprudencia de la Cour establecida a partir del caso Baldus ${ }^{41}$.

Por último, se incorpora como un caso de fuerza al abuso del estado de necesidad o de dependencia (art. 1142), conocida en Derecho francés como violencia económica (violence économique). Esta figura había sido ya reconocida por la Cour de cassa$t i o h^{42}$. La norma no exige que quien abusa de la posición dominante necesariamente obtenga una ventaja excesiva del contrato o que en este exista un desequilibrio excesivo entre las contraprestaciones, sino que la

${ }^{40}$ Huber (2015), pp. 478-479.

${ }^{41}$ Civ. $1^{\text {a }}, 3$ de mayo de 2000, JCP 2000, II, p. 10.510, note Christophe Jamin. Si no se cumplen los requisitos del dolo, en todo caso el contratante afectado puede solicitar la indemnización de perjuicios sobe la base del mencionado art. 1129 .

${ }^{42}$ Civ. 30 de mayo de 2000, D. 2000, p. 879, nota Jean Pascal Chazal; Civ. 3 de abril de 2002, D. 2002, p. 1860, nota Jean Pascal Chazal. 
voluntad de contratar de la parte afectada derive justamente de su estado de necesidad o dependencia. En este sentido, la norma es más cercana al art. 4:109 de los PECL ("Beneficio excesivo o ventaja injusta") que al art. 3.2.7 de los PICC ("Excesiva desproporción"). Como consecuencia de lo anterior, la sanción es la nulidad del contrato y no se admite, como en las normas de Derecho Uniforme, la posibilidad de que el juez restablezca el equilibrio económico del contrato ${ }^{43}$.

\section{b. 4) El contenido del contrato.}

\section{La supresión de la causa}

La subsección 3, sobre "El contenido del contrato", sin duda constituye una de las mayores innovaciones de la reforma. Como se dijo, la supresión formal de la causa y del objeto como requisitos para la validez del contrato serán tratados con mayor detalle más adelante.

Esta subsección contiene normas que, aunque no lo indiquen expresamente, sustituyen diversas funciones que la causa ha cumplido en el Derecho de Contratos francés. El Proyecto sigue en esta materia al Proyecto Terré, aunque la supresión de la causa había sido ya planteada en proyectos de reforma anteriores. Así, el proyecto de la Chancellerie había reemplazado la "causa" por el "interés", estableciendo en su art. 85:

${ }^{43} \mathrm{Al}$ incluirse como un caso de vicio del consentimiento, puede interpretarse en el sentido que su objeto es controlar que el consentimiento se manifieste de manera libre y espontánea, sin tener relación con el equilibrio de las prestaciones. En este sentido, MAZEAUD (2009).
"Cada parte debe tener un interés en el contrato que justifique su obligación (engagement)".

Al respecto, alguna doctrina señaló que se trataba meramente de una sustitución formal o terminológica que no cambiaba en forma sustancial el concepto de causa y las funciones que ha desempeñado en el Derecho Privado francés ${ }^{44}$.

El concepto y las funciones de la causa es quizá uno de los temas más debatidos por la doctrina en el Derecho de Contratos francés. Así, por ejemplo, se habla de causa final, eficiente, objetiva, subjetiva, abstracta, del contrato, de la obligación, inmediata, entre otras ${ }^{45}$. En virtud de lo anterior, se ha señalado:

"En una lectura imparcial de la doctrina francesa contemporánea, es prácticamente imposible saber qué es lo que significa o denota la causa" ${ }^{46}$.

En el mismo sentido, el informe del grupo de trabajo de la Cour de cassation al Proyecto Catala recomendaba la eliminación de la causa, principalmente por su carácter vago e, incluso, incomprensible para los demás ordenamientos jurídicos europeos. En este sentido, debe tenerse presente que ninguno de los instrumentos de

${ }^{44}$ Houtcieff (2009), quien destaca el peligro de reemplazar la noción de causa por otra igual de imprecisa y vaga como la de interés, sin el desarrollo doctrinario de la doctrina de la causa.

${ }^{45}$ Op. cit., p. 199.

${ }^{46}$ GHestin (2005). 
Derecho Uniforme de Contratos reconoce a la causa como un elemento de existencia o validez del contrato ${ }^{47}$.

No obstante la exclusión de la causa de los requisitos de validez del contrato, el Proyecto contiene normas en las cuales pueden reconocerse algunas de las principales funciones que la doctrina y la jurisprudencia han atribuido a la causa. Así, el art. 1161 estipula:

"El contrato no podrá sustraerse al orden público ni en su contenido ni en su finalidad, la conocieren o no todas las partes",

haciendo alusión implícitamente a la denominada causa subjetiva. Por otra parte, el art. 1167 señala:

"Un contrato a título oneroso será nulo cuando, al tiempo de su formación, la contraprestación convenida en provecho de quien se compromete sea ilusoria o irrisoria",

y el 1168 dispone:

"Toda cláusula que prive de su sustancia a la obligación esencial del deudor se tendrá por no escrita".

${ }^{47}$ Así, por ejemplo, el art. 2:101 de los PECL, sobre las condiciones para la celebración del contrato, establece que el contrato se perfecciona si las partes tienen la intención de obligarse legalmente y alcanzan un acuerdo suficiente, sin necesidad de ninguna otra condición. El texto tiene la intención de descartar a la causa y a la consideration como requisitos para el perfeccionamiento de un contrato.
En ambas normas propuestas puede reconocerse a la denominada "causa objetiva". La última de dichas normas es la consagración de la jurisprudencia Chronopost de la Cour de cassation, por la cual se reputó como no escrita una cláusula limitativa de responsabilidad que fijaba una suma irrisoria de perjuicios por inejecución de la obligación principal del deudor ${ }^{48}$. En dicho caso, la Cour fundamentó su decisión en que una cláusula como la descrita privaba de objeto a la obligación del deudor y, por tanto, de causa a la del acreedor. Las normas propuestas han hecho que se señale que en el fondo, nuevamente, se trata solo de una supresión formal, subsistiendo en forma implícita el concepto de causa y los problemas asociados a su determinación y aplicación ${ }^{49}$.

Sin perjuicio de lo señalado sobre la causa, esta subsección contiene otras reglas novedosas. En cuanto a la determinación del precio, el proyecto adopta la regla establecida por la jurisprudencia de la Cour de cassation, en virtud de la cual se permite la fijación unilateral del precio en los contratos marco (contrats cadre) y en los de ejecución sucesiva (art. 1163) ${ }^{50}$. Una regla similar se establece para los contratos de prestación de servicios, en que a falta de acuerdo antes de la ejecución del contrato, el precio puede ser fijado por el acreedor (art. 1164). En ambos casos, la determinación del precio está eventualmente sujeta a la revisión del

${ }^{48}$ Com. 22 de octubre de 1996; D. 1997, p. 121, note Alain Sèrieux; RTD civ. 1997, p. 148, obs. Jacques Mestre.

${ }^{49}$ GRIMALdi (2015), pp. 814-815.

${ }^{50}$ Destacadamente, Ass. plen. 1 de diciembre de 1995, Bull. Ass. plen $\mathrm{N}^{\circ} 9$. 
juez en caso de una fijación abusiva, lo que es una innovación en relación con la jurisprudencia de la Cour, que solo admite la terminación del contrato o la indemnización de perjuicios para dicho caso. La norma, en todo caso, es más restrictiva que la contenida en el Proyecto Terré, donde se admitía de manera general en su art. 60 respecto del objeto de la obligación.

Los artículos propuestos, al restringir la regla a ciertos tipos de contratos, son coherentes con el art. 1591 del Code, que dispone para el contrato de compraventa que

"El precio deberá ser determinado y establecido por las partes".

No obstante, la tendencia en el ámbito comparado es a establecer como regla general la posibilidad de que el precio quede indeterminado al momento de la celebración del contrato o que pueda ser fijado unilateralmente por una de las partes, sin que esto afecte la validez del contrato (arts. 55 de la CVCIM, art. 5.1.7 de los PICC, 6:104 a 6:107 de los PECL).

El art. 1169, en otro de los temas que con seguridad traerán mayor polémica, introduce al texto del Code civilla sanción a las cláusulas abusivas. La norma propone:

"Una cláusula que crea un desequilibrio significativo entre los derechos y obligaciones de las partes puede ser suprimida por el juez a petición del contratante a cuyo detrimento se hubiere estipulado".
Como puede apreciarse, la norma no distingue entre contratos de libre discusión y de adhesión, y basta el desequilibrio significativo, sin exigir que se haya contravenido la buena fe. El inciso segundo de la norma sigue la regla comúnmente establecida en el ámbito europeo, excluyendo de la apreciación del desequilibrio a las cláusulas relativas al objeto del contrato y a la adecuación del precio a la prestación ${ }^{51}$.

La inclusión de una norma general sobre cláusulas abusivas en el Code civil puede considerarse como la culminación de una evolución legislativa y jurisprudencial en la materia. A partir de la ley No. 95-96 de 1 de febrero de 1995, el art. 132-1 del Código del Consumo estableció:

"En los contratos celebrados entre profesionales y no profesionales o consumidores, son abusivas las cláusulas que tiene por objeto o por efecto producir, en perjuicio del no profesional o del consumidor, un desequilibrio significativo entre los derechos y obligaciones para las partes del contrato".

De dicha norma, dos cosas pueden destacarse: lo relevante es el desequilibrio en los derechos y obligaciones de las partes, y la norma se aplica no solo en beneficio de los consumidores sino, también, de los no profesionales. La Cour de cassation había fallado que los jueces de fondo podían exami-

${ }^{51}$ Directiva $93 / 13$ sobre cláusulas abusivas, art. 4.2 . 
nar y sancionar las cláusulas abusivas sin necesidad de texto expreso ${ }^{52}$. Por último, por la ley $\mathrm{N}^{\mathrm{O}}$ 2008-776 de 4 de agosto de 2008, se estableció en el art. L. 442-6, I, $2^{\circ}$ que debe reparar el daño causado

"todo productor, comerciante, industrial o persona inscrita en el Registro Central de Artesanos, por el hecho de: $2^{\circ}$ Someter o intentar someter a un colaborador comercial a obligaciones que provoquen un desequilibrio significativo en los derechos y obligaciones de las partes" ${ }^{\prime 3}$.

Complementado la regla ya citada del propuesto art. 1169, el art. 1170 deja claro que, sin embargo, se man134 tiene la tradición francesa de excluir a la lesión como causal general de nulidad del contrato, al disponer:

"En los contratos sinalagmáticos, la falta de equivalencia de las obligaciones no es una causa de nulidad del contrato, a menos que la ley disponga lo contrario".

\section{b. 5) Sanciones. La nulidad}

La sección 4 sobre "Las sanciones", también contiene algunas novedades importantes. La nulidad sigue requiriendo pronunciamiento judicial, pero se abre la posibilidad de que ambas

\footnotetext{
${ }^{52}$ Civ. $1^{\text {a }} 14$ demayode $1991, N^{\circ} 89$, p. 20.999, D. 1991, p. 449, nota Jacques Ghestin.

${ }_{53}$ Traducción disponible en www.legifrance.gouv.fr [Fecha de consulta: 9 de abril de 2015].
}

partes declaren el contrato nulo de común acuerdo (1178). La misma norma otorga expresamente a la parte afectada por la nulidad, acción para demandar los perjuicios que hubiese sufrido, si se cumplen los requisitos de la responsabilidad extracontractual, lo cual implica, al menos, un actuar culposo de la otra parte. Esta regla se encuentra también en los PICC (art. 3.2.16) y los PECL (art. 4:117), con la precisión que se exige que el contratante responsable haya debido o debido saber del vicio que invalidaba el contrato, y limitando los perjuicios al interés negativo. La nulidad parcial es acogida en el art. 1185, siguiendo la tendencia en Derecho Comparado y uniforme (arts. 3.2.13 de los PICC, 4:116 de los PECL y II.- 7:213 del DCFR).

\section{b. 6) Interpretación del contrato}

El capítulo III del Proyecto, sobre la interpretación del contrato, también modifica sustancialmente la normativa vigente (arts. 1156 a 1164). Si bien el criterio principal de interpretación sigue siendo la intención común de los contratantes, cuando dicha intención no puede ser determinada, el contrato deberá interpretarse según el sentido que le daría una persona razonable en la misma situación que los contratantes (art. 1188), norma similar al art. 4.1 de los PICC y 5:101 de los PECL. La protección de la parte débil se hace presente en la regla que señala que en caso de duda, la obligación deberá interpretarse contra el acreedor y en favor del deudor (art. 1190); y que en caso de ambigüedad, las cláusulas de un contrato de adhesión se interpre- 
tan en contra de la parte que las ha propuesto (art. 1193).

b. 7) Los efectos del contrato

El capítulo IV del Proyecto, relativo a los efectos del contrato, comienza regulando los efectos entre las partes, con el efecto obligatorio en la subsección 1, la cual es encabezada por la reproducción parcial del conocido art. 1134 del Code civil:

"Los contratos legalmente celebrados tendrán fuerza de ley entre quienes los han celebrado. Podrán ser modificados o revocados por mutuo consentimiento o por las causas que autoriza la ley".

La propuesta elimina el actual inciso tercero que se refiere al deber de ejecutar las convenciones de buena fe; y cambia el término convención o acuerdo (convention) por contrato. Asimismo, el art. 1195 del proyecto reproduce el actual art. 1135:

"Los contratos obligan no solo a lo expresado en ellos, sino también a todas las consecuencias que la equidad, la costumbre o la ley le atribuyan a la obligación según su naturaleza".

A continuación, se introduce expresamente al Code la teoría de la imprevisión (art. 1196), estableciendo la obligación de renegociación del contrato para las partes y una limitada facultad al juez para revisar el acuerdo. Debe recordarse que la pro- cedencia de la teoría de la imprevisión ha sido constantemente denegada por la Cour de Cassation desde el famoso caso del Canal de Craponne ${ }^{54}$. Solo por excepción, fundada en el deber de buena fe en la ejecución de los contratos (arts. 1134 inc. 3), una reciente, pero consistente jurisprudencia de la Cour ha establecido la existencia de un deber de renegociar en los casos en que la obligación de una de las partes ha devenido en excesivamente onerosa, alterando de manera radical el equilibrio contractual ${ }^{55}$.

El propuesto art. 1196 sigue en la materia al Proyecto de la Chancellerie $(\text { art. 136) })^{56}$, disponiendo:

"Si un cambio de circunstancias imprevisible al tiempo de la celebración del contrato hace la ejecución excesivamente onerosa para una parte que no había aceptado asumir tal riesgo, ésta podrá solicitar una renegociación del contrato a la otra parte. La primera parte seguirá cumpliendo sus obligaciones durante la renegociación. En caso de negativa o de fracaso de la renegociación, las partes podrán soli-

${ }^{54}$ Canal de Craponne, Civ. 6 de marzo de 1876, DP 1876.I.197. La doctrina del fallo ha sido confirmada con posterioridad en reiteradas ocasiones.

55 "Arrêt Huard", Com, 3 November 1992, D. 1995, Somm. p. 85, note D. Ferrier; "Arrêt Chevassus-Marge", Com. 24 November 1998, D. 1999, IR p. 9; Civ. 16 de marzo de 2004, $D$. 2004 Somm. p. 1754, nota Denis Mazeaud; CA Nancy $2^{\text {nd }}$ Ch. Com. 26 de septiembre de 2007.

${ }^{56} \mathrm{El}$ art. 92 del Proyecto Terré permitía la modificación judicial del contrato sin requerir acuerdo de las partes para dicho efecto. 
citar de común acuerdo al juez que proceda a la adecuación del contrato. En su defecto, una parte podrá solicitar al juez que ponga fin al contrato, en la fecha y los términos que éste estime oportunos".

Se establece, por tanto, como efecto primario del cambio de circunstancias, un deber de renegociación entre las partes. Aun cuando la norma no lo indica, debe presumirse que la negativa injustificada de una parte a entrar en negociaciones o la conducta de mala fe durante las mismas, la hará responsable de los perjuicios que correspondan. El juez solo puede intervenir en caso de que la renegociación no prospere, estando facultado para modificar el acuerdo exclusivamente si hay acuerdo de las partes para ello. En caso contrario, podrá poner fin al contrato, contando con amplias facultades para establecer los efectos de dicha terminación ${ }^{57}$.

La subsección 2 se refiere al efecto traslaticio del contrato (art. 1197), explicitando que en los contratos que tienen por objetivo la enajenación de la propiedad o de otro derecho, la transferencia opera desde la celebración del contrato, pudiendo, definir la transferencia por la voluntad de las partes (mediante una cláusula de reserva de dominio), la naturaleza de las cosas (si el objeto del contrato es una cosa genérica) o la ley. Se confirma así la regla tradicional del Derecho francés, actualmente contenida en los

\footnotetext{
${ }^{57}$ Por esta vía podría el juez, al menos indirectamente, intervenir en el contenido del contrato.
}

arts. 711, 1136 y 1138 del Code. La norma agrega que la transferencia de la propiedad importa también la transferencia del riesgo de la cosa, salvo que el deudor se haya constituido en mora de entregar (art. 1322-1) o que las partes acuerden lo contrario (por ejemplo, hasta la entrega material).

La sección 2 se ocupa de los efectos del contrato respecto de terceros, estableciendo expresamente el efecto relativo (art. 1200), pero al mismo tiempo indicando:

"Los terceros deben respetar la situación jurídica creada por el contrato" (art. 1201).

En esta sección se regulan también la promesa de hecho ajeno (art. 1205) y la estipulación en favor de otro (arts. 1206 a 1210).

La sección 3 es una novedad para el Code, ya que se ocupa de "La duración del contrato", estableciendo, entre otras reglas, que en el caso de los contratos de duración indeterminada, cualquiera de las partes puede ponerle término en cualquier momento, dando aviso en un plazo razonable, no siendo responsable por dicho término unilateral sino en caso de abuso (art. 1212).

b. 8) El incumplimiento

y los remedios del acreedor

Una de las secciones más interesantes del proyecto es la sección 4 sobre "El incumplimiento del contrato", que sistematiza una materia que se encontraba dispersa en el texto original del Code, cuyo tratamiento es considerado por la mayoría de la doctrina como 
defectuoso ${ }^{58}$. Comienza dicha sección con la enumeración de los remedios del acreedor ante el incumplimiento del deudor. La utilización del galicismo remède es ya una innovación importan$\mathrm{te}^{59}$. Dichos remedios son la suspensión de la obligación propia, la ejecución forzada, la reducción del precio, la resolución y la indemnización de perjuicios (art. 1217). La norma excluye una jerarquización de los remedios disponibles para el creedor y expresamente señala que aquellos que no son incompatibles pueden ser acumulados, disponiendo que la indemnización de perjuicios puede demandarse junto con cualquier otro remedio.

La subsección 1 reglamenta la excepción de contrato no cumplido (l'exception d'inexécution), la cual no había sido regulada por el Code, estableciendo que una parte puede negarse a cumplir su prestación cuando la no otra no ha ejecutado la suya y dicho incumplimiento es suficientemente grave (art. 1219). El art. 1220 introduce como novedad la posibilidad que una parte suspenda la ejecución de su prestación cuando es manifiesto que la otra parte no cumplirá y las consecuencias de dicho incumplimiento serán graves para ella.

La regulación de la ejecución forzada también presenta novedades (subsección 2). Ella deja de ser el remedio o efecto primario del acreedor ante el incumplimiento y se señala que ella no procederá si la ejecución es imposible o manifiestamente irrazonable (art. 1221). Se eliminan, entonces, las distinciones entre obligaciones de dar, hacer

${ }^{58}$ TAllon (1994), p. 223.

${ }^{59}$ Así lo había hecho ya el Proyecto Terré. y no hacer, estableciendo un régimen único. El texto, en lo formal, se separa de la distinción que en la materia hacen los instrumentos de Derecho Uniforme, los cuales distinguen entre la ejecución forzada de obligaciones dinerarias y no dinerarias (arts. 7.2.1 y 7.2.2 de los PICC, 9:101 y 9:102 de los PECL).

La resolución por incumplimiento se regula sistemáticamente en la subsección 4, dejando de estar regulada a propósito de las obligaciones condicionales (actual art. 1184), e introduciendo las soluciones jurisprudenciales y doctrinarias que se han desarrollado en la materia.

En primer lugar, sin limitarla a los contratos bilaterales, el art. 1224 dispone que la resolución resulta de la operación de una cláusula resolutoria, o en caso de incumplimiento grave, de la notificación del acreedor o de una decisión judicial.

El proyecto acepta la resolución unilateral (art. 1226), señalando que el acreedor puede, en caso de incumplimiento grave y a su riesgo, resolver el contrato por medio de la notificación al deudor. Se trata de la consagración de la jurisprudencia de la Cour, que desde 1998 ha permitido la resolución unilateral, sin necesidad de sentencia judicial previa, cuando el incumplimiento grave de la otra parte así lo justifica ${ }^{60}$. Se sigue la tendencia en Derecho Uniforme: arts. 7.3.1. de los PICC y 9:301 de los PECL. Empero se ha rechazado la posibilidad de la resolución por incumplimiento an-

${ }^{60}$ Civ. 1, 13 de octubre de 1998, Bull. civ. I, No 300; D. 1999, p. 197, nota Christophe Jamin; RTD civ. 1999, p. 374, obs. Jacques Mestre. 
ticipado, ampliamente aceptada otros sistemas tanto de Derecho Civil (por ejemplo, art. 349 Código Civil alemán) como de Common Law (con la figura del anticipatory breach), lo mismo que en Derecho Uniforme de contratos (arts. 7.3.3 y 7.3.4 de los PICC, 9:304 de los PECL) ${ }^{61}$.

No obstante, se mantiene en cierta medida un control sobre la resolución que efectúa el acreedor, ya que se requiere, además del incumplimiento grave, que el acreedor dé aviso al deudor moroso y le otorgue un plazo razonable para cumplir (inc. 2 art. 1226). El deudor puede, además, siempre objetar ante el juez la resolución, y es el acreedor quien tiene la carga de probar la gravedad del incumplimiento (inc. 4 art. 1226). Mantiene así, el Derecho francés, un resguardo 138 (al menos formal) importante de los intereses del deudor, cuestión que no sucede en el Derecho Uniforme.

El juez mantiene amplias atribuciones en caso de que la resolución se ejerza por vía judicial. Así, puede constatar o pronunciar la resolución, $\mathrm{u}$ ordenar la ejecución del contrato, concediendo eventualmente al deudor un plazo para cumplir (art. 1228) ${ }^{62}$.

Si bien el proyecto establece solo que "La resolución pone fin al contrato" (art. 1229 inc. 1), sin adoptar la fórmula del Proyecto Terré y del Derecho Uniforme en cuanto a expresar que la resolución opera hacia el futuro (art. 115 del Proyecto Terré, 7.3.5 de

${ }^{61}$ El Proyecto Terré también la admitía en su art. 111.

${ }^{62} \mathrm{Al}$ efecto, véase Civ. $1^{\mathrm{a}}$, 7 de noviembre de 2000, Bull. Civ. I, No 286, D. 2001, Somm. 1137, obs. Denis Mazeaud, D. 2001, Somm. 256, obs. Christophe Jamin. los PICC y 9:305 de los PECL), el art. 1229 puede interpretarse en el sentido de que la resolución carece, en principio, de efectos retroactivos, sin perjuicio de los efectos restitutorios que produce. La norma señala que la resolución no afecta las cláusulas relativas a la solución de controversias, ni aquellas destinadas a producir efectos en el caso de resolución del contrato (1230). Las restituciones que las partes deban hacerse se rigen por el nuevo capítulo v del título IV.

La sección sobre incumplimiento del contrato concluye con la regulación de la indemnización de perjuicios (subsección 5, arts, 1231 a 1231-7). Nuevamente, el mérito del proyecto es la sistematización de las reglas desarrolladas por la doctrina y la jurisprudencia. El art. 1231-1 establece que el deudor deberá indemnizar los perjuicios siempre que no justifique que la inejecución de la obligación proviene de una causa extraña que no pueda serle imputada. Las normas siguientes agregan que la indemnización incluye el daño emergente y el lucro cesante (art. 1231-2) ) $^{63}$, los perjuicios previstos o que pudieron preverse, salvo en caso de dolo (art. 1231-3), pero siempre que sean resultado inmediato y directo del incumplimiento (art. 1231-4).

Asimismo, manteniendo la regla introducida en 1975 al $\mathrm{Code}^{64}$, se facul-

${ }^{63}$ Sin explicitar, como lo hacía el Proyecto Terré (art. 118), que la indemnización debe dejar al acreedor en la posición en que se encontraría si el contrato si hubiese ejecutado (interés positivo).

${ }^{64}$ Art. 1152, modificado por la ley de 9 de julio de 1975 y posteriormente por la ley de 11 de octubre de 1985. 
ta al juez para moderar o aumentar el monto de los perjuicios establecido por medio de una cláusula penal en caso que ella sea manifiestamente excesiva o irrisoria. El juez puede rebajar proporcionalmente la pena en caso de cumplimiento parcial (art. 1231-5). Esta norma es de orden público y no puede, por tanto, ser derogada por las partes.

\section{Consideraciones finales}

Sin perjuicio de que el Proyecto consagra una serie de instituciones desarrolladas por la doctrina y la jurisprudencia francesas, deliberadamente se aleja del modelo tradicional francés en cuestiones esenciales como la supresión de la causa y el reconocimiento de la teoría de la imprevisión. Lo anterior, unido a la sanción amplia a las cláusulas abusivas, permite concluir que este es un proyecto de ruptura y no solo de adecuación o continuidad.

El papel del juez también se transforma. Por una parte, situaciones tradicionalmente reservadas a la decisión judicial, como la resolución por incumplimiento, se dejan ahora al arbitrio de la parte afectada. Así, en general, los remedios del acreedor ante el incumplimiento se hacen efectivos mediante la notificación de aquel al deudor. La intervención del juez en la mayoría de los casos es solo a posteriori, a modo de control que el ejercicio de los derechos por parte acreedor se efectúe de acuerdo con la ley.

Por otra parte, el papel del juez se refuerza, en particular con la finalidad de preservar el contrato y de proteger a la parte débil de la relación. Así sucede, por ejemplo, con la facultad del juez para revisar el precio que ha sido fijado de manera abusiva unilateralmente por uno de los contratantes, la eventual (pero limitada) posibilidad de revisar el contrato en caso de imprevisión, la concesión de un plazo al deudor para cumplir o la adecuación de la cláusula penal.

El Proyecto reconoce en varios aspectos la influencia del Derecho Internacional y europeo de Contratos, y en tal sentido pone en línea al Derecho de Contratos francés con los desarrollos contemporáneos en la materia. Ello es visible ya en la estructura del Proyecto, así como en el reconocimiento de la buena fe como principio general, en las reglas sobre retractación de la oferta y formación del consentimiento (teoría de la recepción), en la interpretación del contrato según el sentido que le otorgue una persona razonable y en la resolución unilateral por notificación. Sin perjuicio de ello, el Proyecto mantiene también algunas instituciones propias de la tradición francesa, como la distinción entre nulidad absoluta y relativa, la distinción entre distintos casos de error y las normas particulares en que se mantiene la necesidad de una contraprestación real para la validez del contrato (arts. 1167 y 1168).

En este sentido, cabe destacar nuevamente una de las motivaciones principales de la reforma, cual es volver a poner al Derecho francés como un modelo de inspiración para otros ordenamientos jurídicos, un modelo "exportable" y atractivo no solo para 
los contratantes sino, también, para países que pretendan reformar su derecho de contratos y obligaciones en el siglo Xxi ${ }^{65}$. Habrá que esperar el texto definitivo del Proyecto, y más importante, su evaluación por la doctrina y demás operadores jurídicos, para comprobar si el Derecho de Contratos francés vuelve a la posición de privilegio que ocupó hasta las primeras décadas del siglo Xx.

\section{Bibliografía CitAdA}

Association Henri Capitant (2006). Les Droits de tradition civiliste en question: A propos des Rapports Doing Business de la Banque Mondiale. Paris: Société de Législation Comparée, 2 vols.

Aubert de Vincelles, Carole (2009). "Les principes généraux relatifs au droit des contrats", in François TERRÉ (dir.). Pour une réforme du droit des contrats: Réflexions et propositions d'un groupe du travail sous la direction de François Terré. Paris: Dalloz.

Cabrillac, Rémy (2008). "Le Project de réforme du droit des contrats: Premières impressions". Juris-Classeur périodique, édition Générale, Paris. Vol. I.

Cartwright, John, Stefan Vogenauer \& Simon Whittaker (eds.) (2009). Reforming the French Law of Obligations - Comparative Reflections on the Avant-projet de réforme du droit des obligations et de la prescription ('the Avant-projet Catala). Oxford and Portland: Hart Publishing.

${ }^{65}$ En este sentido, véase FAUvarQue-CosSON (2006), p. 147.
Castets Renard, Céline (2010). "Les projets de réforme du droit français des contrats". Osaka University Law Revierw. $\mathrm{N}^{\circ}$ 57. Osaka.

Catala, Pierre (2006), "Presentación general del Ante-Proyecto", en Del contrato, de las obligaciones y de la prescripción. Ante-Proyecto de Reforma del Código Civil Francés. Libro III, títulos III $y X X$. (trad.) Fernando Hinestrosa. Bogotá: Universidad Externado de Colombia

Catala, Pierre (2007). "L'avant-projet de réforme des obligations et le droit des affaires". Revue de jurisprudence commercial. $\mathrm{N}^{\circ} 3$, vol. 182. $\mathrm{Pa}-$ ris.

Fabre-Magnan, Muriel (2008). "Réforme de droit des contrats: 'Un très bon projet'. Juris-Classeur périodique, édition Générale. Paris. Vol. I.

Fauvarque-Cosson, Bénédicte (2006). "La réforme du droit français des contrats: perspective comparative". $R D C . \mathrm{N}^{\mathrm{O}} 1$. Paris.

Fauvarque-Cosson, Bénédicte, Denis Mazeaud (eds.) (2008). European contract law: Materials for a common frame of reference: Terminology, guiding principles, model rules. Munich: Sellier.

Fontaine, Marcel (2004), OHADA Uniform Act on Contract Law. Explanatory Notes to the Preliminary Draft, disponible en www.unidroit.org/english/legalcooperation/ OHADA $\% 20$ explanatory $\% 20$ notee.pdf. [Fecha de consulta: 23 de abril de 2015].

Ghestin, Jacques (2005). "Faut-il conserver la cause en droit européen des contrats?". European Review of Contract Law. Vol. 4. Berlin. 
Grimaldi, Cyril (2015). "Les maux de la cause ne sont pas qu'une affaire de mots". Recueil Dalloz. No 814815. Paris.

Hondius, Ewoud (2007). "The Two Faces of the Catala Projet-Towards a New General Part of the French Law of Obligations". European Review of Private Law. Vol. $15 \mathrm{~N}^{\circ}$ 6. Utrecht.

Houtcieff, Dimitri (2009). "Le contenu du contrat", in François TERRÉ (dir.), Pour une réforme du droit des contrats: Réflexions et propositions d'un groupe du travail sous la direction de François Terré. Paris: Dalloz.

Huber, Peter (2015). "Art. 3.2.2", in Stefan Vogenauer (ed.). Commentary on the UNIDROIT Principles of International Commercial Contracts (PICC). Oxford: Oxford University Press.

Mazeaud, Denis (2009). "La réforme du droit français des contrats: trois projets en concurrence", in Sarah Bros y Blandine MALlet-Bricout (coords.), Liber amicorum Christian Larroumet. Paris: Economica.

Mazeaud, Denis (2010). "La réforme du droit français des contrats". Revue Juridique Thémis. No 44. Montréal.

NotTAGe, Luke (2015). "Art. 2.1.2", in Stefan Vogenauer (ed.). Commentary on the UNIDROIT Principles of International Commercial Contracts (PICC). Oxford: Oxford University Press.

Principes contractuels communs: Projet de cadre commun de référence. (Droit privé comparé et européen; v. 7 Y). Paris: Société de Législation Comparée, 2008

Remy-Corlay, Pauline et Dominique Fenouillet (2009). "Le consete- ment”, in François Terré (dir.). Pour une réforme du droit des contrats: Réflexions et propositions d'un groupe $d u$ travail sous la direction de François Terré. Paris: Dalloz.

SARgos, Pierre (2009). "The Work of the Cour de cassation on the Avantprojet de réforme", in John CARTWRIGHT, Stefan VogenAUER \& Simon WhitTAKer (eds.). Reforming the French Law of Obligations - Comparative Reflections on the Avant-projet de réforme du droit des obligations et de la prescription ('the Avant-projet Catala'). Oxford and Portland: Hart Publishing.

Tallon, Denis (1994). "L'inexécution du contrat: pour une autre présentation". Revue trimestrielle de droit civil. Paris.

Tallon, Denis (2006). "Teneur et valeur du projet appréhendé dans une perspective comparative". Revue des contrats. $\mathrm{N}^{\mathrm{O}} 1$. Paris.

Terminologie contractuelle commune: Projet de cadre commun de référence (Droit privé comparé et européen; v. $6 \mathrm{Y}$ ), Paris: Société de Législation Compare, 2008.

Terré, François (2009). Pour une réforme du droit des contrats: Réflexions et propositions d'un groupe du travail sous la direction de François Terré. Paris: Dalloz.

Vogenauer, Stefan (2009). "The Avantprojet de reforme: An Overview", in John Cartwright, Stefan VogeNAUER \& Simon WhitTaKer (eds.). Reforming the French Law of Obligations - Comparative Reflections on the Avant-projet de réforme du droit des obligations et de la prescription ('the Avant-projet Catala'). Oxford and Portland: Hart Publishing. 
Vogenauer, Stefan (2015). “Article 1.7”, in Stefan Vogenauer (ed.). Commentary on the UNIDROIT Principles of International Commercial Contracts (PICC). Oxford: Oxford University Press.

Witz, Claude (2009). "Contrat ou acte juridique?", in François Terré (dir.). Pour une réforme du droit des contrats: Réflexions et propositions d'un groupe du travail sous la direction de François Terré. Paris: Dalloz.

\section{Jurisprudencia citada}

Civ. 6 de marzo de 1876, DP 1876.I.197.

Com. 7 de enero de 1981, Bull. Civ. Iv, $\mathrm{N}^{\mathrm{o}} 14$, RTD civ., 1981 , p. 849 , obs. François Chabas.

Civ. $1^{\text {a }} 14$ de mayo de $1991, N^{\circ} 89$, p. 20.999, D. 1991 , p. 449 , nota
Civ. 1, 13 de octubre de 1998, Bull. civ. I, $\mathrm{N}^{o} 300 ;$ D. 1999, 197, nota C. Jamin; RTD civ. 1999, 374, obs Jacques Mestre

Com. 24 November 1998, D. 1999, IR p. 9.

Civ. $1^{\text {a }}, 3$ de mayo de 2000, JCP 2000, II, p. 10510, note Christophe Jamin

Civ. 30 de mayo de 2000, D. 2000, p. 879 , nota Jean-Pascal Chazal

Civ. $1^{\text {a }}, 7$ noviembre 2000, Bull. Civ. I, No 286, D. 2001, Somm. p. 1137, obs. Denis Mazeaud, D. 2001, Somm. 256, obs. Christophe Jamin.

Com. 12 de febrero de 2002, CCC 2002, p. 90, obs. Laurent Leveneur

Civ. 3 de abril de 2002, D. 2002, p. 1860, nota Jean-Pascal Chazal

Com. 26 Noviembre 2003, Bull. Civ. Iv, $\mathrm{N}^{\circ} 186, D .2004$, p. 869 , nota Anne-Sophie Dupré-Dallemagne

Civ. 16 de marzo 2004, D. 2004 Somm. p. 1754, nota Denis Mazeaud.

Civ. $3^{\text {a }} 25$ de mayo de 2005, Bull. Civ. III $\mathrm{N}^{\circ} 117$, D. 2005 , p. 2837 , obs. Soraya Amrani Mekki

Civ. $3^{\text {a }}, 28$ de junio de 2006, Bull. civ. III $\mathrm{N}^{\mathrm{o}}$ 168, JCP 2006 II, p. 10.130, obs. Olivier Deshayes.

Com. 22 de octubre de 1996; D. 1997, p. 121, note A. Sérieux; RTD civ. 1997, 148, obs. Jacques Mestre.
CA Nancy $2^{\text {nd }}$ Ch. Com. 26 de septiembre de 2007. 